\section{Female feticide}

Rajendra Kale, in his editorial entitled "'It's a girl' - could be a death sentence" sheds light on the despicable societal forces that lead women to abort female fetuses preferentially. He subsequently advocates for physician regulatory agencies to undertake a recommendation to ban the disclosure of the sex of a fetus before 30 weeks gestation. This advocacy is misguided at best and dangerous at worst.

Current Canadian policy recognizes that a woman seeking an abortion is normally in the best position to make this complex decision. Providing optimal medical care should then include providing her with as much information as possible. This should include the sex of the fetus if requested. This may mean that a woman is making a decision to have an abortion for reasons that Dr. Kale describes as "repugnant." But, taking the decision out of the hands of women is not the solution. Even when a woman seeks an abortion because of coercion, she may well be making the best decision to keep herself and her other children safe. As Dr. Kale points out, having a female baby can put a woman at risk of discrimination, isolation from her community, abuse and, in extreme cases, murder. Blaming women for the scourge of gender-based violence is also not a solution. This is why limiting access to abortion based on this specific reason is dangerous health policy. Does this mean that some women will decide to abort female fetuses preferentially? Sadly, yes.

\section{Susan J. Woolhouse MD}

South Riverdale Community Health Centre, Toronto, Ont.

\section{Reference}

1. Kale R. "It's a girl!" - could be a death sentence. CMAJ 2012;184:387-8.

CMAJ 2012. DOI:10.1503/cmaj.112-2044

CMAJ's recent editorial "It's a girl!"could be a death sentence," highlights an important issue that has been underaddressed in Canada. Skewed sex ratios have indeed been documented in subgroups of Quebec. ${ }^{2}$ What is not clear, however, is the extent to which delayed disclosure of fetal gender would be sufficient to prevent sex selective abortion. Late pregnancy abortions are not unheard of in Canada, ${ }^{3}$ and parents who are motivated enough could paradoxically revert to this option. The longterm solution might instead lie in closer attention to gender inequality as a determinant of health at a global level. Forces worldwide are leading to greater intermingling of cultures with different perspectives on status of women, and it is unlikely that sex-selective abortions can be reduced without conscious efforts to raise awareness of gender equality at all levels of society.

\section{Nathalie Auger MD MSc, Harbhajan S. Kang MD \\ University of Montréal (Auger),}

Montréal, Que; and Montréal, Que. (Kang)

\section{References}

1. Kale R. "It's a girl!" - could be a death sentence. CMAJ 2012; 184:387-8.

2. Auger N, Daniel M, Moore S. Sex ratio patterns according to Asian ethnicity in Quebec, 19812004. Eur J Epidemiol 2009;24:17-24.

3. Auger N, Denis G. Late pregnancy abortions: an analysis of Quebec stillbirth data, 1981-2006. Int J Public Health 2012;57:443-6.

\section{CMAJ 2012. DOI:10.1503/cmaj.112-2045}

"Should female feticide in Canada be ignored because it is a small problem localized to minority ethnic groups?" To this question Dr. Rajendra Kale firmly responds "no."' Disagreeing with him would be difficult given existing policies.

The Canadian Medical Association statement on abortion from 1988 indicates, that prior to viability, abortion should be made universally available throughout Canada. ${ }^{2}$ The sex of the fetus is typically not considered medically relevant; however, the policy statement does not state that abortion requires a medically relevant indication. There may be many nonmedical reasons abortion is procured, which could include poor timing of conception, not wanting more children, an abusive household environment, financial strain, sexual assault, fetal chromosomal abnormalities and defects. ${ }^{3}$

From a patient perspective, the most concordant statement is from the Abortion Rights Coalition of Canada. Their position statement from 2006 states that, in regard to sex-selective abortion, "it is important to remember that we cannot restrict women's right to abortion just because some women might make decisions we disagree with." ${ }^{4}$

As physicians, however, we are not obligated to provide nonmedical information regarding the fetus, and this is where I agree with Dr. Kale. The Society of Obstetricians and Gynecologists has already stated that they "do not support the termination of pregnancy on the basis of gender."' 5 From a provider perspective, Dr. Kale's proposal to provide sex typing at 30 weeks is a balanced way to provide information to future parents without actively being involved in the selection process. Whether this would need to be mandated or left to individual providers would be open to further debate.

Patient education is important because physicians cannot prevent patients from obtaining ultrasounds elsewhere - and we shouldn't, if we are allowing patient autonomy as per the Abortion Rights Coalition of Canada statement. We must also be prepared to deal with an increase in child abuse and infanticide in at-risk groups. This will require the education of primary care providers in identifying susceptible patients, and the development of resources to which these patients can be referred.

\section{Justin E.J. Kopp}

University of Saskatchewan,

Saskatoon, Sask.

\section{References}

1. Kale R. "It's a girl!" - could be a death sentence. CMAJ 2012; 184:387-8.

2. The Canadian Medical Association. CMA policy: induced abortion. Ottawa $(\mathrm{ON})$ : The Association 1988. Available: http://policybase.cma.ca/dbtw-wpd /PolicyPDF/PD88-06.pdf (accessed 2012 Feb. 7).

3. Kirkman M, Rowe H, Hardiman A, et al. Reasons women give for abortion: a review of the literature. Arch Womens Ment Health 2009;12:365-78.

4. Abortion Rights Coalition of Canada. Position paper \#24: Sex selection abortions. Vancouver (BC): The Coalition; 2006. Available: www.arcc-cdac.ca/postion papers/24-Sex-Selection-Abortions.pdf (accessed 2012 Feb. 7).

5. Society of Obstetricians and Gynaecologists of Canada. SOGC policy statement: statement on gender selection. Ottawa (ON): The Society; 2007. Available: www.sogc.org/guidelines/documents /guiJOGC198PS0711.pdf (accessed 2012 Feb. 7).

CMAJ 2012. DOI:10.1503/cmaj.112-2046 